\title{
Pan Arab Interventional Radiology Society-PAIRS: A Milestone for Interventional Radiology in the Arab World - Reminiscences on the Founding of the Society
}

Dear Colleagues,

As we celebrate the $10^{\text {th }}$ anniversary of Pan Arab Interventional Radiology Society (PAIRS) and the inaugural issue of our new journal, the Arab Journal of Interventional Radiology (AJIR), I look back at the early days of the Society and the great efforts that each and every one of the members have put in, with much satisfaction and more optimism for the future of IR in the Arab World.

I was asked to contribute to the AJIR with a short editorial about the history of PAIRS having had the high honor of being the Founding President. I thought that the best contribution would be to publish my inaugural speech at the First PAIRS Scientific Meeting in Dubai in January 2006. The distinguished international speakers at that meeting included Professor Jacques Moret, Professor Kris Kandarpa, Dr. Tony Nicholson, and Professor Marc Sapoval. There were, of course, presentations from members of the burgeoning Society.

First and foremost, however, I wish to acknowledge the efforts of all the members of the Board of the Society over the last 10 years and particularly the first Treasurer Joe El-Khoury who established the Society accounts and also my successors as Presidents, all of whom have contributed significantly through their wisdom, determination, contacts, and vision to the development and maturation of the Society:

- Hazem Habboub (Jordan): 2008-2010

- Ahmad Sami (Egypt): 2010-2012

- Suzanne Abbas (Bahrain): 2012 (relinquished her position for health reasons)

- Muhammad Al-Shammari (Kingdom of Saudi Arabia): 2012-2015 (extended for 1 year by decision of the AGM to solidify the arrangements for the independent meeting in Dubai)

- Nadia Hammami (Tunisia): 2015-present.

A quick look at the above list illustrates the breadth of representation from the different parts of the Arab World which is embedded in the spirit of the Society.

My inaugural speech was as follows:

“Announcement of PAIRS

Aghiad Al-Kutoubi

President of PAIRS

First Scientific Meeting

Arab Health, Dubai, January $25^{\text {th }}, 2006$,
Ladies and Gentlemen, Distinguished speakers, Colleagues, and Friends.

Today's meeting marks the culmination of many months of preparation, but most importantly, it sets the pace as the first scientific activity of our young society. I am absolutely delighted to see all of you here and thankful to our speakers for taking the trouble to travel all the way here to give us the benefit of their expertise and wisdom. I am also very proud of our joint efforts to promote IR in the Arab World.

The initial discussions over the creation of PAIRS started in 1998 at an interventional meeting in Cyprus directed at the Near East and hosted by Schneider. I had just moved to the American University of Beirut from the UK and was asked to take part in the scientific program. That was the first opportunity for me to meet some of the Arab brothers. I shared and discussed the idea of forming the society with Adel AlAly, Joe El-Khoury, Tariq Linjawi, and Hazem Habboub. Several meetings followed; in Beirut, Cannes, Amman, and Dubai, at which further discussion took place and the goals and shape of the future society were debated. Professor Jacques Moret gave us the benefit of his wisdom at the Amman meeting.

It was at Arab Health last year (January 2005), at a dinner hosted by Cordis that the colleagues present "the founder members" decided to formulate an interim council and make PAIRS a reality. Yesterday's general meeting officially confirmed the presence of the Society and elected the first council.

Over the last 7 years, our efforts to gather and discuss were enthusiastically supported by friends from the industry. I must acknowledge with my personal sincere thanks the help of Mona Kaissi, Musbah Khatib, and Baho Macari from Boston Scientific; Grace Deaibes, Hani Abouhalka, Mariuxi Romero, Hugo Craven, Charbel Mouawad, and Francois Salmon from Cordis J \& J; and Ala'a Hussein from EV3.

Cordis, BS, Gore, and EV3 have generously sponsored our speakers. As in last year, Cordis have also generously hosted the Society dinner.

In addition, Cordis and Medtronic have also pledged 10,000 US\$ each in donation to the Society. I hope that other companies will follow suite.

I am thankful to all of you for honoring me with the presidency of the Society. I also thank you for your confidence on behalf of the members of the Council. 
The aims of the Society are now established in the bylaws. We face many challenges, but at the same time, we have many opportunities to establish, strengthen, promote, and help regulate the practice of IR in the region. We have exciting times ahead and all of us should join hands to achieve our common objectives.

I declare the Pan Arab Interventional Radiology Society established and wish you all a fruitful scientific session."

Following on from the first scientific meeting in Dubai, the Society elected to hold the yearly scientific meetings in conjunction with the Arab Congress of Radiology that was organized by the sister society PAARS. It was felt at the time that combining the efforts will help both societies to solidify the scientific content and focus the efforts of the sponsoring bodies. In this context, the subsequent six scientific meetings of PAIRS were held along the ACR in Jordan, Egypt, Lebanon, and Tunis. The program was invariably excellent with contributions from established international experts and links with CVIR, SIR, and The French IR Society.

It was at the Tunis meeting in 2012 that the AGM of PAIRS discussed the pros and cons of having a joint meeting and reached the decision to hold a separate and independent meeting of PAIRS, and Dubai was chosen as the permanent location of the annual meeting. Extensive efforts were put in by all members of the Board and Society toward the success of the PAIRS 2014 meeting, but I would like to single out the efforts of the then President of the Society Muhammad Al-Shammari in making the meeting such a success and building the foundations for the subsequent meetings. Through his efforts, an annual "winter workshop" in Morocco was also started to strengthen the links with the brothers in Al Maghrib Al Arabi.

Along the road members of the Society participated in the scientific activities, but more importantly, there was, and still remains, a concerted effort to streamline the structure of the Society by updating the bylaws and establishing subcommittees to meet the requirements of a society that has emerged from infancy. An office for the Society was established in Beirut through the efforts of Abbas Chamsuddin, and two full-time employees were engaged to replace Liliane Rizk, who worked part time as an administrator of the Society in its earlier years. A website was created, limited at first, but now an interactive progressive site thanks to the efforts of Karim AbdelTawab. Ayman Sebai succeeded in getting recognition of PAIRS in the UAE which provided some sponsorship and facilitated the opening of a Society account for future use. Another milestone was reached when the Society approved the establishment of a scientific publication to be called the Arab Journal of Interventional Radiology-AJIR. Mohammad Arabi was named the first editor of this journal, and you are now seeing the fruit of his efforts as you read through this article!
On the international front, and following discussions in Rome in 2006 between myself and the then President of CIRSE, Professor Johannes Lammer, a model for collaboration between the two societies was established and members of PAIRS were given the opportunity to get automatic membership in CIRSE and pay reduced fees for the membership and CVIR. Professor Lammer was invited to the second PAIRS scientific meeting in the Dead Sea, Jordan, and subsequently, PAIRS was one of the first regional societies to be invited by CIRSE to the "CIRSE meets." session at the meeting in Copenhagen in 2008. At that session, there were original contributions from Dr. Hazem Habboub on the treatment of venous male impotence, Dr. Maurice Haddad on the treatment of hydatid disease, and Dr. Adel Ahmad AlAly on regulatory issues of IR in Kuwait. I had the pleasure of representing PAIRS on the International Committee of SIR through the efforts of Professor Kandarpa and gained from their experience in relation to training and regulatory issues as they pertained to PAIRS. Discussions and collaboration initiatives were also conducted with the BSIR/RCR through Professor Andy Adam and the French Society of IR through Professors Francis Joffre and Herve Rousseau. In 2010, PAIRS was a co-signatory to the IR Global Statement defining IR which was initiated by CIRSE and SIR. PAIRS also adopted CVIR as the Society's Scientific Journal.

The symbiotic relationship between the Society and industry needs no emphasizing. We depend on the support of the industry and at the same time provide a forum for the use and evaluation of the various products. A healthy relationship and sponsorship were evident right from the beginning of the Society and I am delighted to see the pattern of "coexistence" continues to thrive.

I am humbled by the confidence and honors that all the members have bestowed on me and mindful of the responsibilities of being elected Honorary Life President in Cairo in 2011 and also the first Fellow of PAIRS in Dubai in 2014 .

I would like to finish this editorial by expressing my personal pride at the way the Society has evolved and developed once again acknowledging the work and contribution of not only all the members who practice IR in the Arab countries but also all our Arab colleagues in Europe and North America who are too many to mention by name and who have made immense contributions to the scientific meetings either by giving presentations or by planning the scientific program of the various annual meetings as well as the winter workshops.

The first meeting attracted nearly 75 interventionalists with representation from our surgical colleagues who were among the founders and continued to contribute to the Society and be present at the scientific meetings. The 2016 PAIRS scientific meeting attracted more than 400 registrants, and I am confident that PAIRS will 
continue to grow and make an impact on the practice of image-guided intervention in the Arab World and globally.

Aghiad Al-Kutoubi

Department of Diagnostic Radiology, IR Division, The American University of Beirut Medical Center, Beirut, Lebanon E-mail:mk00@aub.edu.lb

This is an open access article distributed under the terms of the Creative Commons Attribution-NonCommercial-ShareAlike 3.0 License, which allows others to remix, tweak, and build upon the work non-commercially, as long as the author is credited and the new creations are licensed under the identical terms.

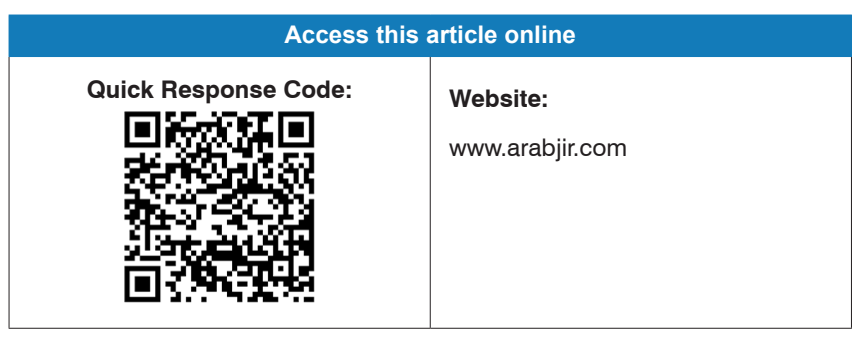

How to cite this article: Al-Kutoubi A. Pan Arab Interventional Radiology Society-PAIRS: A Milestone for Interventional Radiology in the Arab World - Reminiscences on the founding of the society. Arab J Intervent Radiol 2017;1:2-4. 